\title{
HIGH OCCUPANCY VEHICLE LANES ARE AN EXPECTED FAILURE
}

\author{
Yair Wiseman \\ Computer Science Department, Bar-Ilan University \\ Ramat-Gan 52900, Israel \\ wiseman@cs.biu.ac.il
}

\begin{abstract}
HOV lanes are supposed to control the traffic flow and keep it uncongested; nonetheless, HOV lanes require the continuation of the traffic jams and congestions; otherwise they will have no effect. The more traffic jams and congestions take place, the more successful the HOV lanes will be. The absurdity of HOV is that a solution for traffic congestions has a critical need for constant congestions to be successful. In the coming years when autonomous vehicle will be more common, the effectiveness of HOV lanes will be even slighter, but even before the emerging of the autonomous vehicles, the concept of HOV lanes failed in many venues because its reasoning is irrational
\end{abstract}

Keywords - High Occupancy Vehicle Lanes, Traffic Congestions, Autonomous Vehicles, Multi-Level Roads

\section{INTRODUCTION}

HOV (High Occupancy Vehicle) is a reserved traffic lane for a controlled use. Only vehicles occupied by a driver and one or more passengers are allowed to travel in HOV lanes [1].

The technique of (HOV) lanes is a disputable way to eliminate traffic congestions [2,3], for the reason that HOV will succeed to eliminate congestions, only if traffic congestions refuse to go away. I. e. there is a need for ongoing congestions in the general purpose lanes so as to convince the drivers to shift to the HOV lane, otherwise the HOV lanes will have no effect [4].

Actually, HOV lanes are kind of the known effect called "the cobra effect" [5]. The cobra is a dangerous poisonous snake and an occurrence of cobras in populated areas is an acute danger. Therefore, when the British ruled India, they decided to encourage the civilians there to kill cobras by stipulating that any person bringing a cobra carcass would win cash reward.

The result of this stipulation was the opening of cobra farms so as the farm owners would be able to raise and kill cobras and winning the cash reward. Eventually the prize was canceled and the farm owners released the cobras. So in fact the citizen participation program in reducing the cobra population failed and to this day attempts to shape people's behavior, which result in undesirable outcomes are called the "cobra effect".

Figure 1 shows screenshots of the Waze navigation application that show two cases with additional times of 13 minutes and 8 minutes for the travelers in the HOV lane in highway no. 2 in Israel. That is to say travelling in the general purpose lanes will be faster is these two cases than travelling in the HOV lane. 

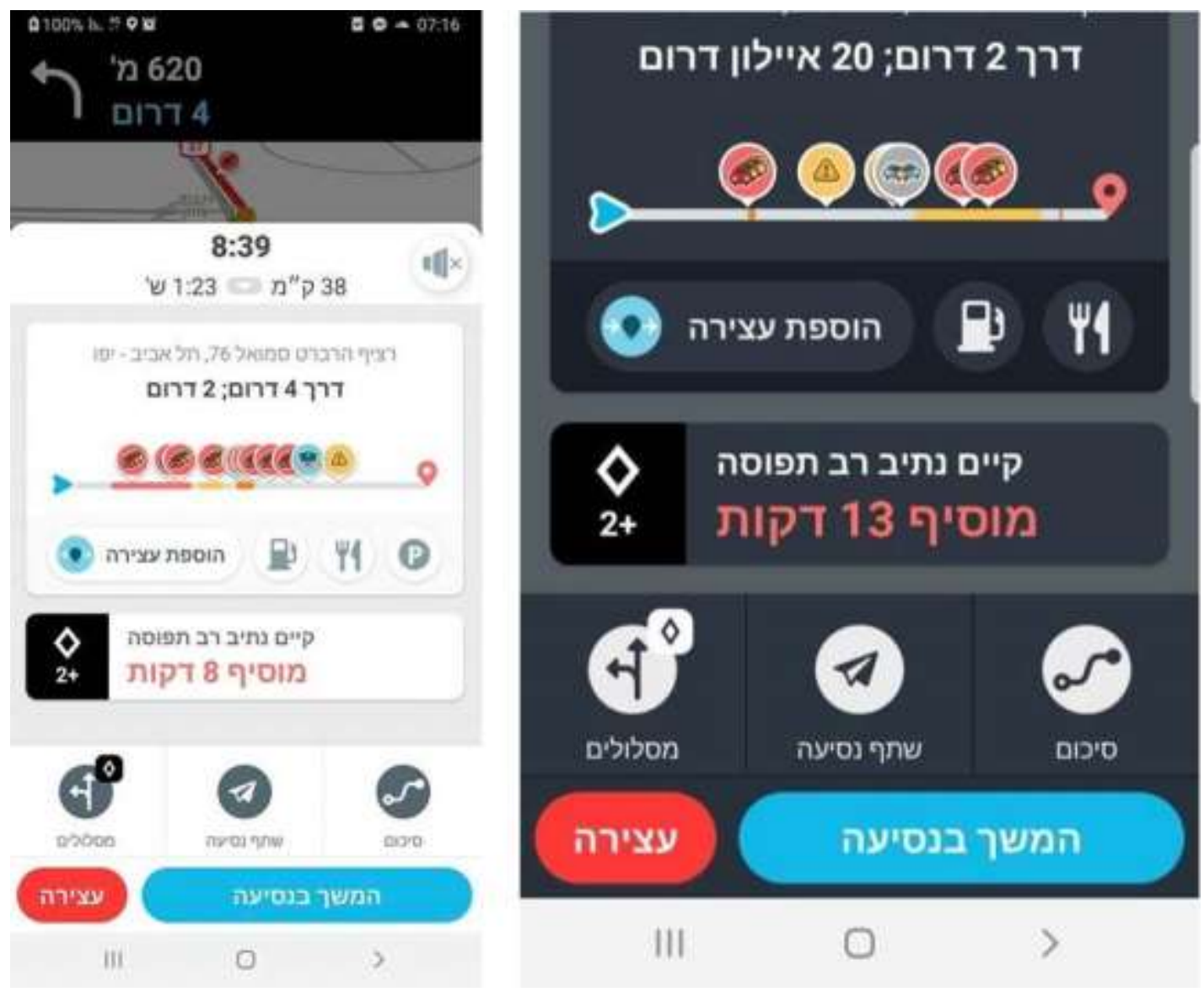

Fig. 1 Additional 8/13 minutes in HOV lanes in Israel

\section{HOV ABSURDITY}

HOV lane's main objective is encouraging drivers to shift to HOV lanes in order to increase the average number of occupants in vehicle by making carpools and so to reduce the number of vehicles on the roads and consequently eliminate the congestions in the roads [6].

Drivers will indeed shift to HOV lanes only there is a significant travel time variance between the HOV lane and the general purpose lanes [7]; however, for such a significant travel time variance, there must be a substantial congestion in the general purpose lanes.

This absurdity is an integral part of HOV lanes. I.e. HOV lanes can eliminate congestions only if the congestions persist. Because of the congestion inevitability, it is quite obvious that construction of HOV lanes is a very questioning and doubtful way to eliminate traffic congestion [8]. 


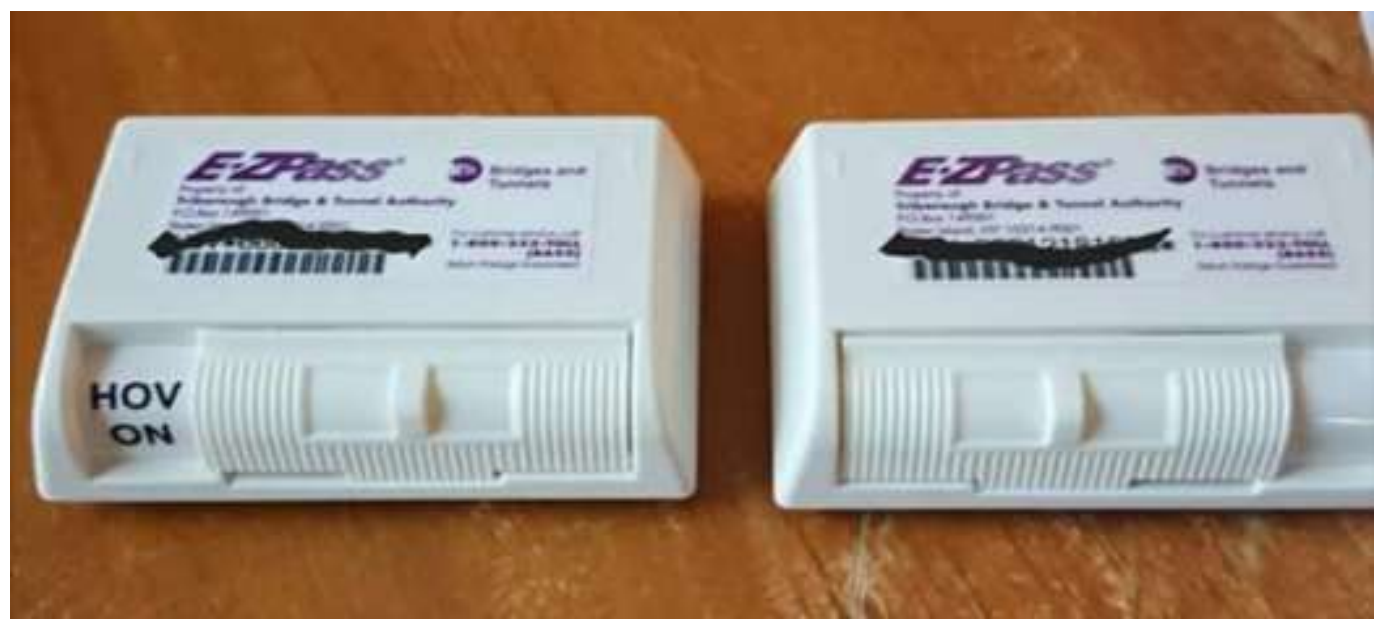

Fig. 2 E-ZPass with HOV switch in Staten Island

As a result, in all the US there are currently HOV lanes in only $0.08 \%$ of the roads. Furthermore, in almost all of these few HOV lanes there is at least one of two exceptions of solo drivers that are allowed to travel, which actually makes the HOV lane a "semi HOV lane":

- Solo drivers that pay a certain toll [9]. E. g. The Staten Island Borough of New York City provides E-ZPass tags with a switch that can be manually set so as to indicate whether the vehicle currently has enough occupants or a toll should be charged as is shown in Figure 2.

- Vehicles that emit considerably less quantity of pollution to the environment compared to conventional internal combustion engine vehicles running on gasoline [10]. In some states like California a special decal is put on the vehicle as can be seen in Figure 3, whereas in some other states like Georgia the license plate indicates that the vehicle is environmentally friendly as can be seen in Figure 4.

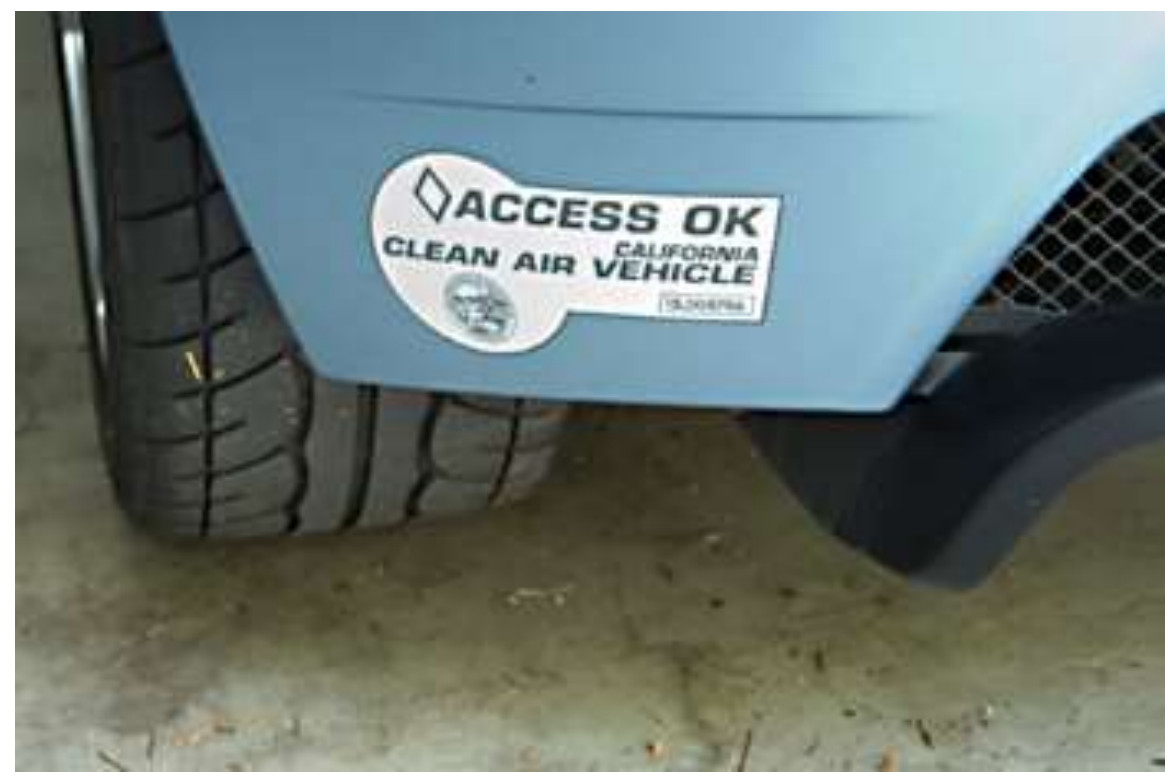

Fig. 3 Clean air decal in California 


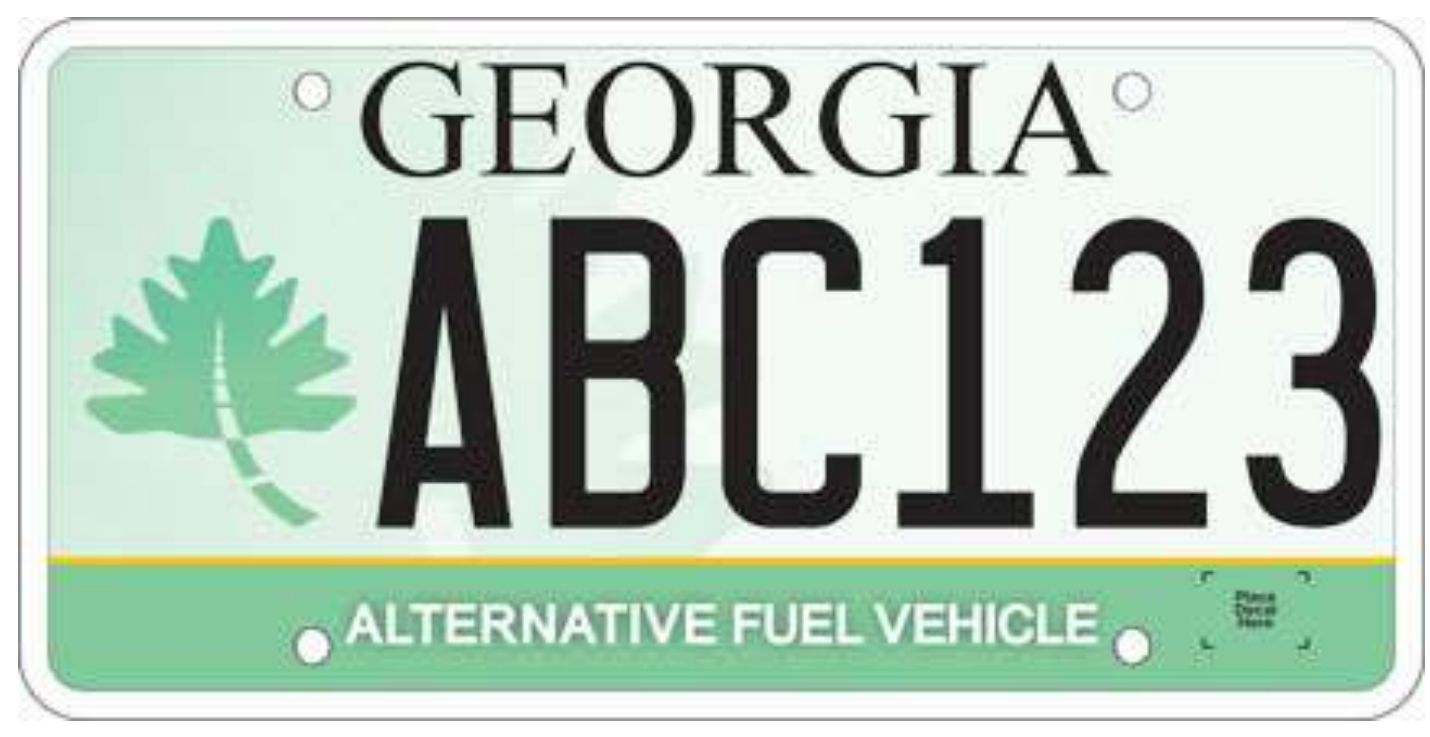

Fig. 4 Clean air license plate in Georgia

\section{NEW JERSEY}

In the 1990s, New Jersey tried to shape the behavior of people on roads. In roads I-287 and I-80, one lane has been turn into a lane that only vehicles with two passengers or more could pass through [11].

The failure of this HOV lane was searing. The traffic jams in the general purpose lanes were presumed; however, the secondary roads from which the highway intersected were jammed and congested. In addition, internal roads parallel to the main road, all of a sudden turn out to be busy roads that got some of the traffic of the main roads.

To overcome the number of occupants restriction, people started to take their children or idle pensioners when they run errands, so their vehicle could travel on the HOV lane. The main motivation for forming the HOV lanes was easing probable congestions. Obviously, this addition of passengers has contributed nothing for easing the congestions.

The end of this saga was in 1998. New Jersey Governor Christine Todd Whitman did a ceremony of removing the HOV signs from both I-80 and I-287. Each and every one applauded her and all the lanes went back to be general purpose lanes and the congestions faded away [12].

\section{LOS ANGELES}

Actually, New Jersey was expected to learn from the failure of a previous similar experiment.

One of the first HOV lanes was in I-10 in a section within Los Angeles called "Santa Monica Freeway". [13] The Director of the California Department of Transportation in 1976 was Adriana Gianturco. She decided to completely stop any new freeway construction in California. She was aware that this stoppage strategy will clearly cause traffic congestions, so as a complementary step she turned lanes in Santa Monica Freeway into HOV lanes.

The experiment lasted five months in 1976. Over these five months, California Department of Transportation observed only very small quantity of shift of solo drivers to carpools or public transportation. The real results showed that their models and expectations were clearly unrealistic and impractical. Instead of easing the traffic congestion, they got worse. 
The protest of the residents was harsh. The campaign started with legitimate actions like sending letters and demonstrations, but when the director of the California Department of Transportation refused to undo the lane conversion, some protesters started to scatter nails in the HOV lanes. Obviously these nails made the congestion even worse.

Eventually after five months, the director of the California Department of Transportation gave up to the protest and admitted defeat. California Department of Transportation turned back the lanes into general purpose lanes and the congestions were reduced.

\section{MASSACHUSETTS}

A year after the failure in Los Angeles, the Massachusetts Department of Transportation converted a general purpose lane in Boston's Southeast Expressway to an HOV lane [14].

The dense arterial road network in this area made it possible to bypass Boston's Southeast Expressway in alternate routes, so there was a worsening in the traffic congestions, but the worsening of the traffic congestions was not very extensive. Nonetheless, many of the drivers were angry at the HOV lane. Furious letters have been sent to Massachusetts governor and to local congressmen. Because 1978 was an election year, the protest was effective and the HOV lane was cancelled after half a year.

The Massachusetts Department of Public Workers explained that the HOV lane did not bring about a significant shift to high occupancy vehicles, but the lane did bring about a substantial inconvenience to Southeast Expressway commuters, so a decision to remove the HOV lane had been taken.

In the half a year when the HOV was operating, ridership at park-and-ride lots remained almost the same and in addition the number of passengers in the rail lines increased merely very slightly.

The negative public atmosphere was also expressed by The Boston Globe that reported about the close down of the HOV lane in a headline: "Diamond dies; no mourners".

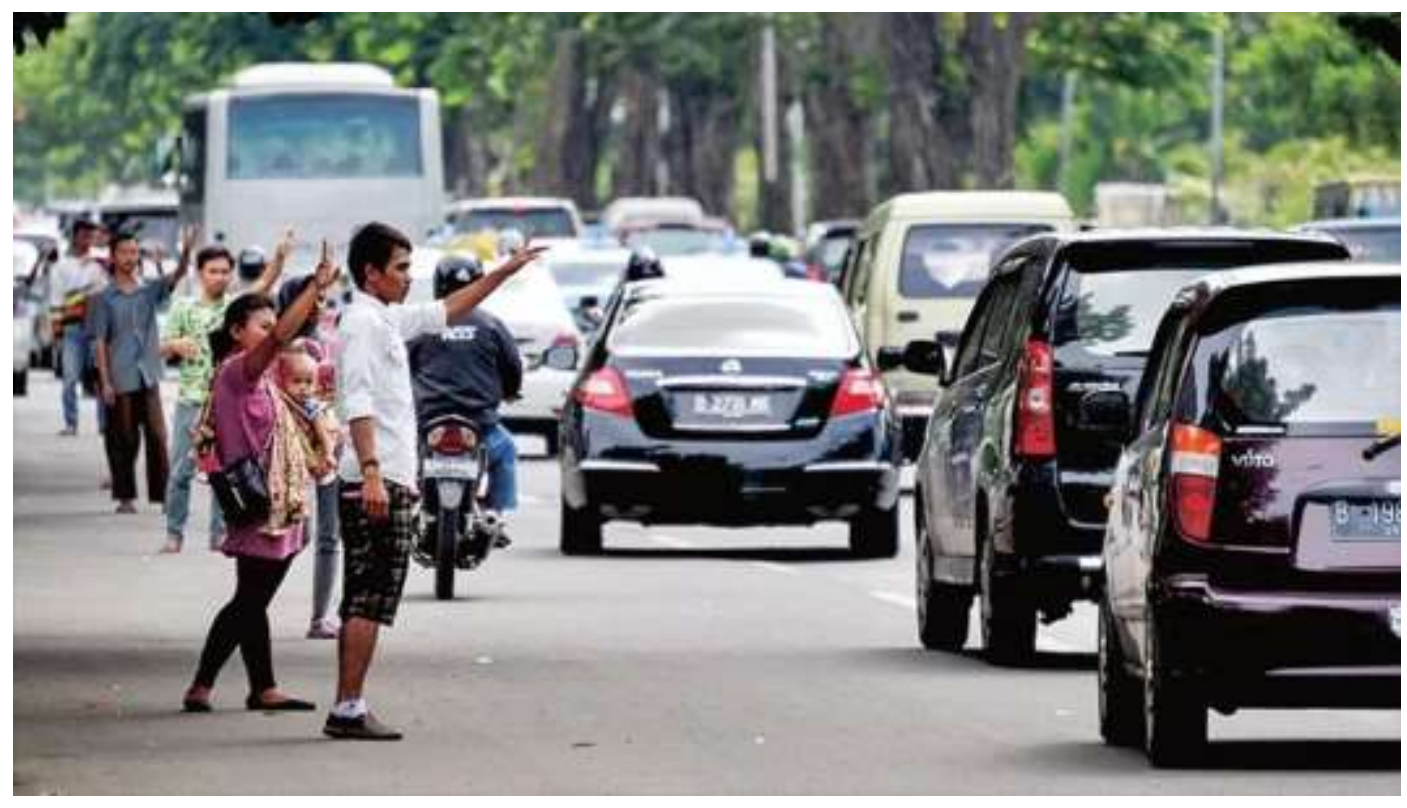

Fig. 5 Paid professional hitchhikers in Jakarta 


\section{JAKARTA}

Jakarta, Indonesia has one of the worst traffic congestion road systems in the world. The city is very dense, so it is hard to expand the number of lanes in the congested roads.

The concept of HOV lanes has come from the US to Indonesia. The Indonesians implemented in 2003 several HOV lanes in roads within Jakarta's central business district [15]. However, in the US it is commonly to consider two or more people in a vehicle as a carpool. Jakarta Transportation Department required three or more people in a vehicle to be considered as a carpool.

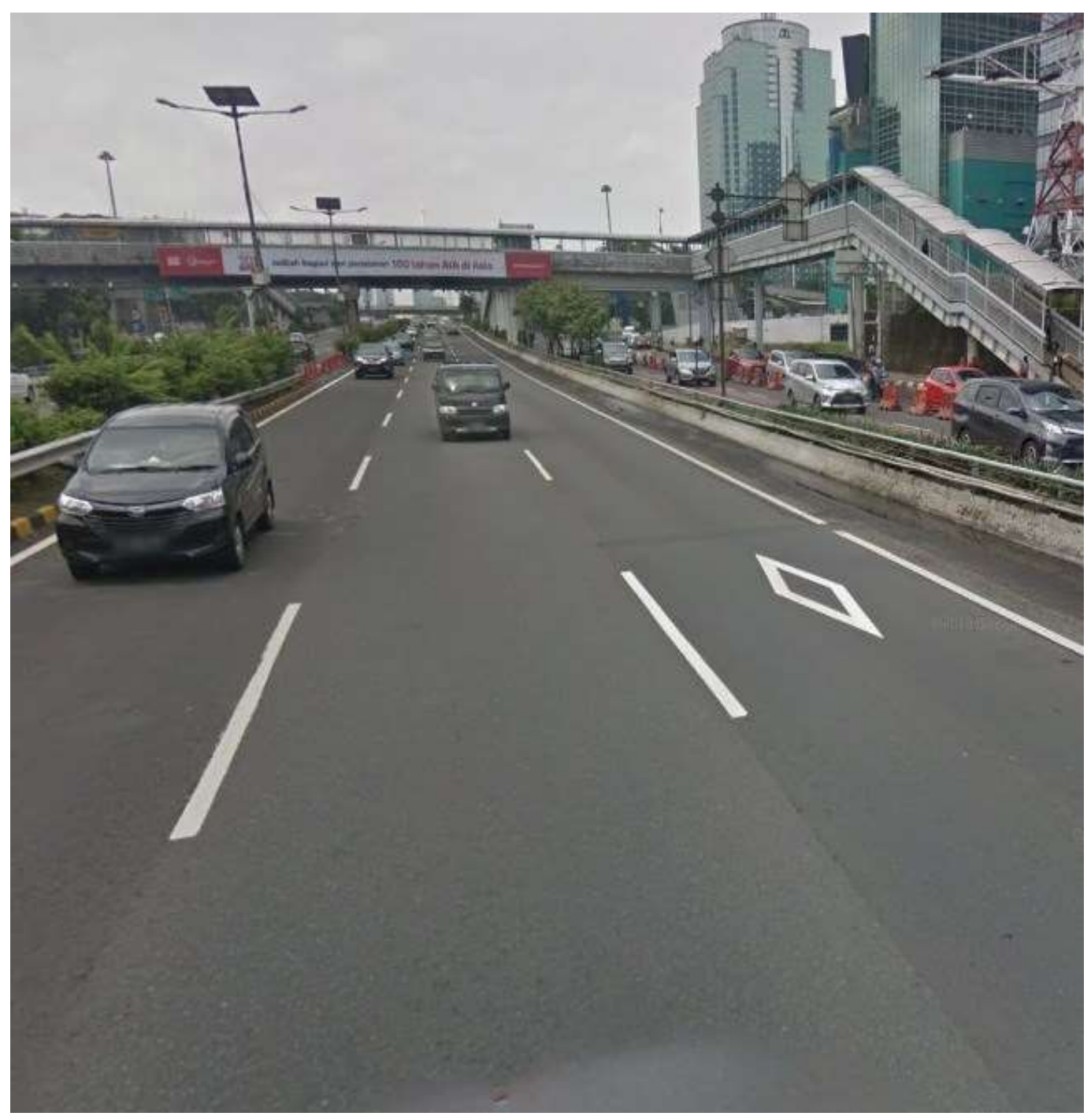

Fig. 6 An HOV lane in Jakarta

The results were again very disappointing and even intolerable. The traffic congestions were even worse. A new job was invented - "paid professional hitchhiker" - Poor people who spent their time to travel back and forth in Jakarta roads. These hitchhikers were paid by drivers who traveled alone and wanted to be able to use the HOV lanes. Figure 5 is a picture of such paid professional hitchhikers. One of women there holds a baby in order to meet the requirement of three or more occupants in the vehicle. 
The experiment lasted 13 years until 2016 when the HOV lanes in Jakarta were eventually acknowledged as a failure by nearly everyone and therefore the HOV lanes were cancelled. The marking of the roads have been retained as can be seen Figure 6 from 2019; however, it is absolutely legal to travel on these lanes even with only solo driver.

\section{AUTONOMOUS VEHICLES}

The new technology of autonomous vehicles will be widely available in the coming years [16]. The autonomous vehicles are already permissible in several states in the US (Arizona, California, Michigan and Ohio) with even no need for a backup driver. It looks like many other states in the US and also other countries will join them in the coming years [17].

In [18] the authors evaluates the driverless car costs. Their conclusion is that public transportation will not be able to be economically competitive to autonomous vehicles. Only in cases where transportation demands can be bundled to larger units, public transportation can be moneymaking and cost-effective. Practically, such transportation demands will come about just in dense urban regions, where HOV lanes are usually not implemented.

Because of the autonomous vehicle cost-effectiveness and the much more comfortable atmosphere for the passenger, it is more than reasonable that the future of the transportation is in autonomous vehicles [19]. Accordingly the main capital spending of the government should be in paving roads that will be able to accommodate the autonomous vehicles rather than railways [20,21].

The autonomous vehicles will be sometimes empty when they go to park themselves remotely $[22,23]$ or when they go to pick up a passenger; however, the problem of parking seekers who slow down the traffic and according to [24] are responsible to $30 \%$ of the traffic congestions in San Francisco, will be disappeared, because it will possible to send the vehicle to park itself distantly.

Studies in a range of countries have indicated that most of traffic congestions and jams are generated from different drivers who response differently to incidents in the roads and have different ways of driving [25, 26]. Oppositely, autonomous vehicles of even competing companies will usually take decisions much the same way, so the nuisance of traffic congestions is going to be considerably eased when the autonomous vehicles are widespread.

Autonomous vehicles will be also able to travel in platoons [27]; i.e. to travel in the same speed and the same distance between the vehicles for a long distance [28]. This ability will also ease the traffic congestions that as was mentioned above are mainly generated by different way of driving.

HOV lanes will be ineffective in the world of autonomous vehicles that travels in the same speed and the same distance between the vehicles, because in such a road system with vehicles travel in platoons, there will not be a noticeable priority to the carpooled vehicles.

\section{MULTI-LEVEL ROADS}

HOV lanes are implemented instead of an additional lane because of two main reasons:

1. There is no room to construct an additional lane in the road, because of nearby building or a problematic terrain that makes the additional lane paving impossible. 
2. The construction costs of new lanes can be too expensive and even unaffordable for the Transportation Department/Ministry, so HOV might be more cost-effective.

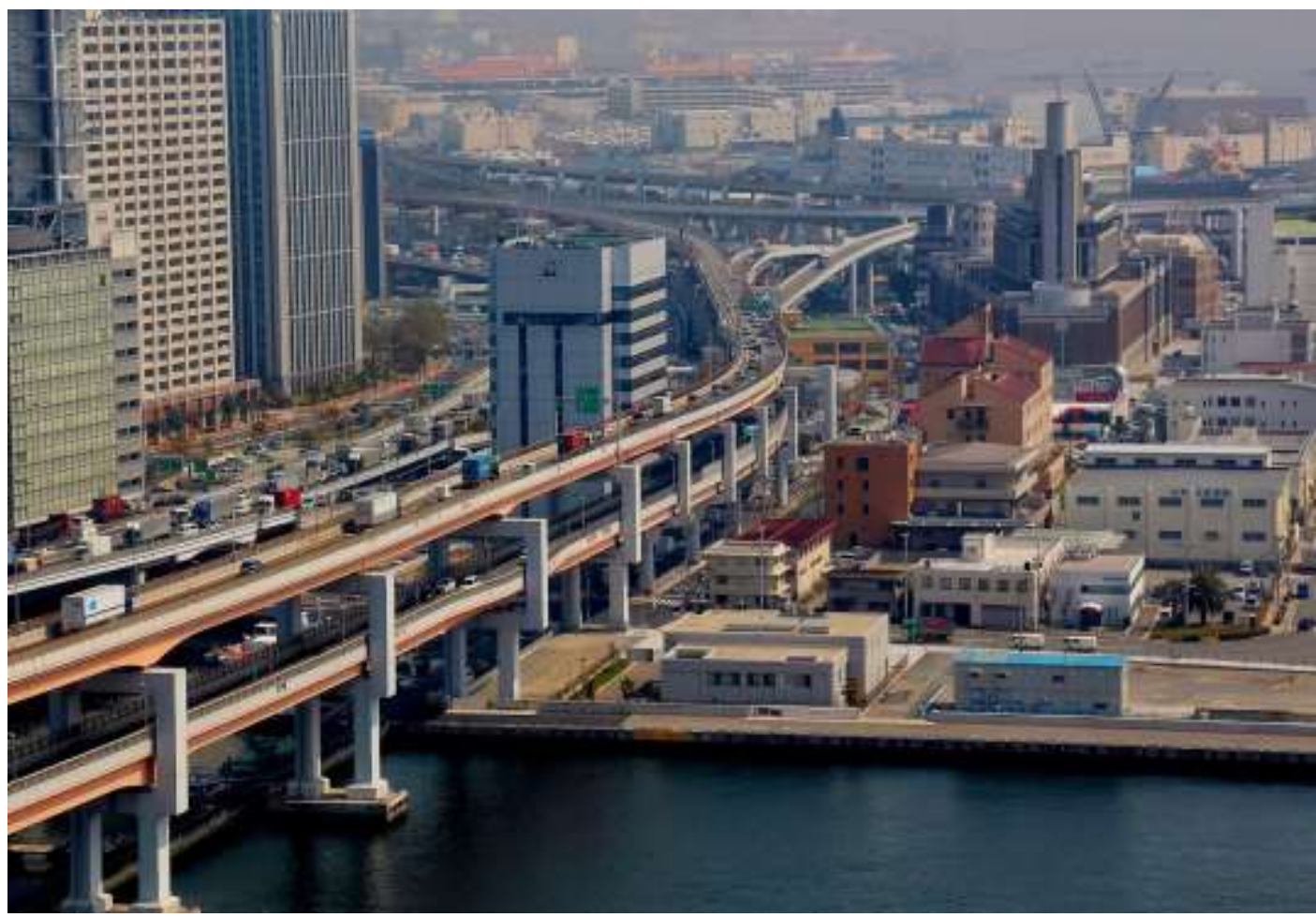

Fig. 7 Two level road in Kobe, Japan

The first issue is discussed in this section and second issue is discussed in the next section.

The first issue can be addressed by construction of a second level of lanes above the existing lanes [29]. Multi-level roads are already implemented in several locations in different parts of the world. Nowadays, these multilevel roads are sometimes built in overcrowded and jammed cities in order to alleviate the traffic congestion problems they experience.

Multi-level road is the solution that was chosen in the city of Kobe in Japan because the city is a home for more than 2.5 million residents; nevertheless its area is only $552.23 \mathrm{~km}^{2}$, so the city is overcrowded. An example of a two level road in Kube is shown in Figure 7.

The city of Chicago in the US is also very dense, especially in the downtown area, so several multi-level roads and streets have been built in order to alleviate the congestion problems. Most of the multi-level roads in Chicago have just two levels. However, there are also 6 three level roads in Chicago.

The Wacker Drive three-level road is shown in Figure 8. 


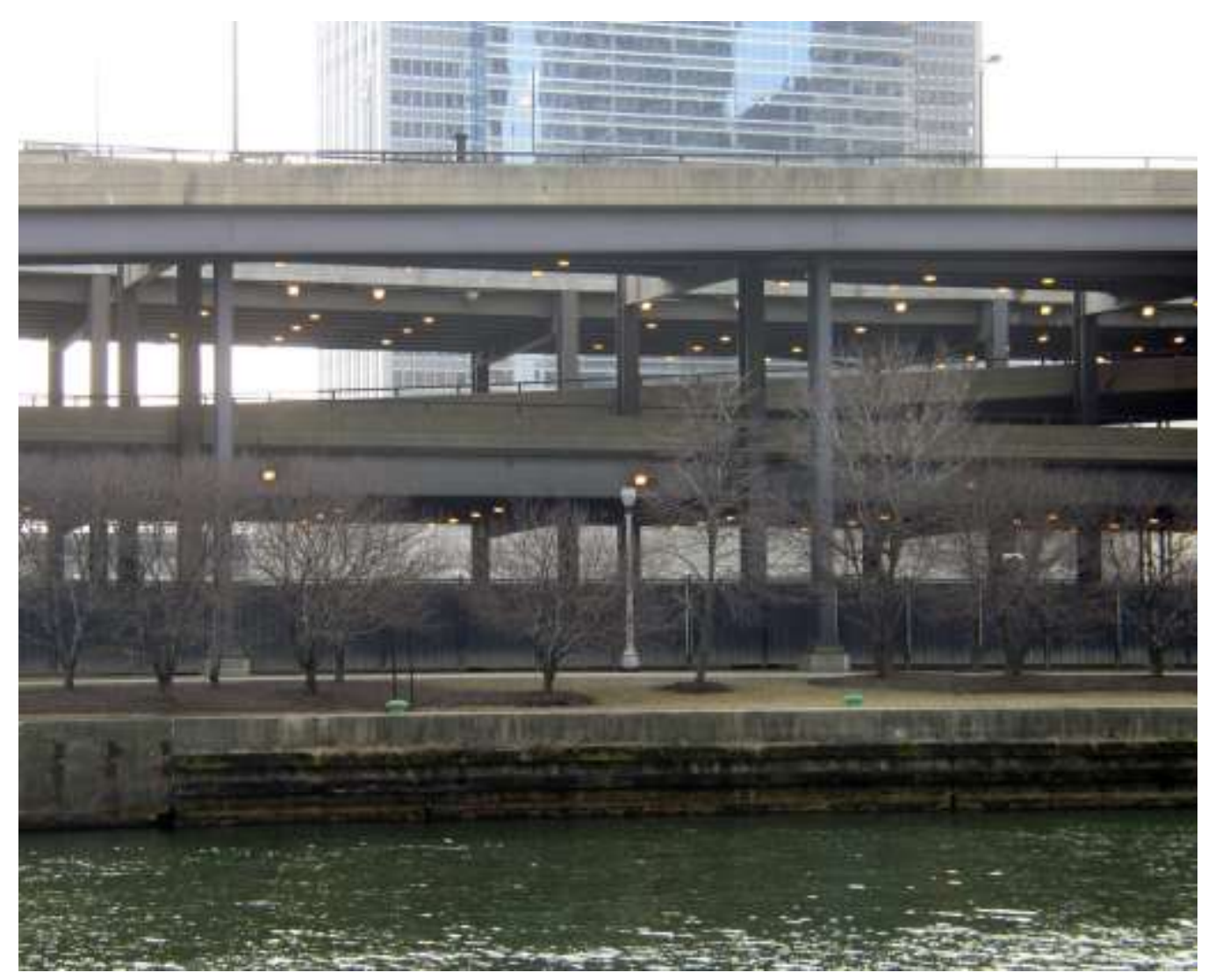

Fig. 8 Multi-level road in Chacago

Many other countries in the world also employed this solution to the traffic congestions. The multilevel roads are not employed just in developed countries. Even Iran which is a developing country implemented the multi-level road solution [30]. The Transportation ministry of Iran built a second floor of lanes above the highway that goes across Tehran.

\section{COST-EFFECTIVENESS OF CONTROLLING ACCESS TO HOV LANES}

The second issue is the open to discussion cost-effectiveness of adding a new lane instead of converting general purpose lane to a HOV lane. Controlling access to HOV lane is regularly used to control the flow of traffic on HOV lanes. Controlled access allows the HOV traffic flowing with minimal disruptive influences caused by frequently entering and exiting vehicles.

Barrier separated HOV lanes from adjacent lanes are sometime used. Also access using grade-separated ramps is sometimes employed. Such ways and means can provide controlled access for high occupancy vehicles so as to smoothly connect with park-and-ride lots or transit centers. In this way, the controlled access allows HOV traffic keeping away from freeway interchanges served by other traffic. Another possible occurrence of direct access ramp usage is when there is a need to connect one HOV lane to its peer HOV lane. 


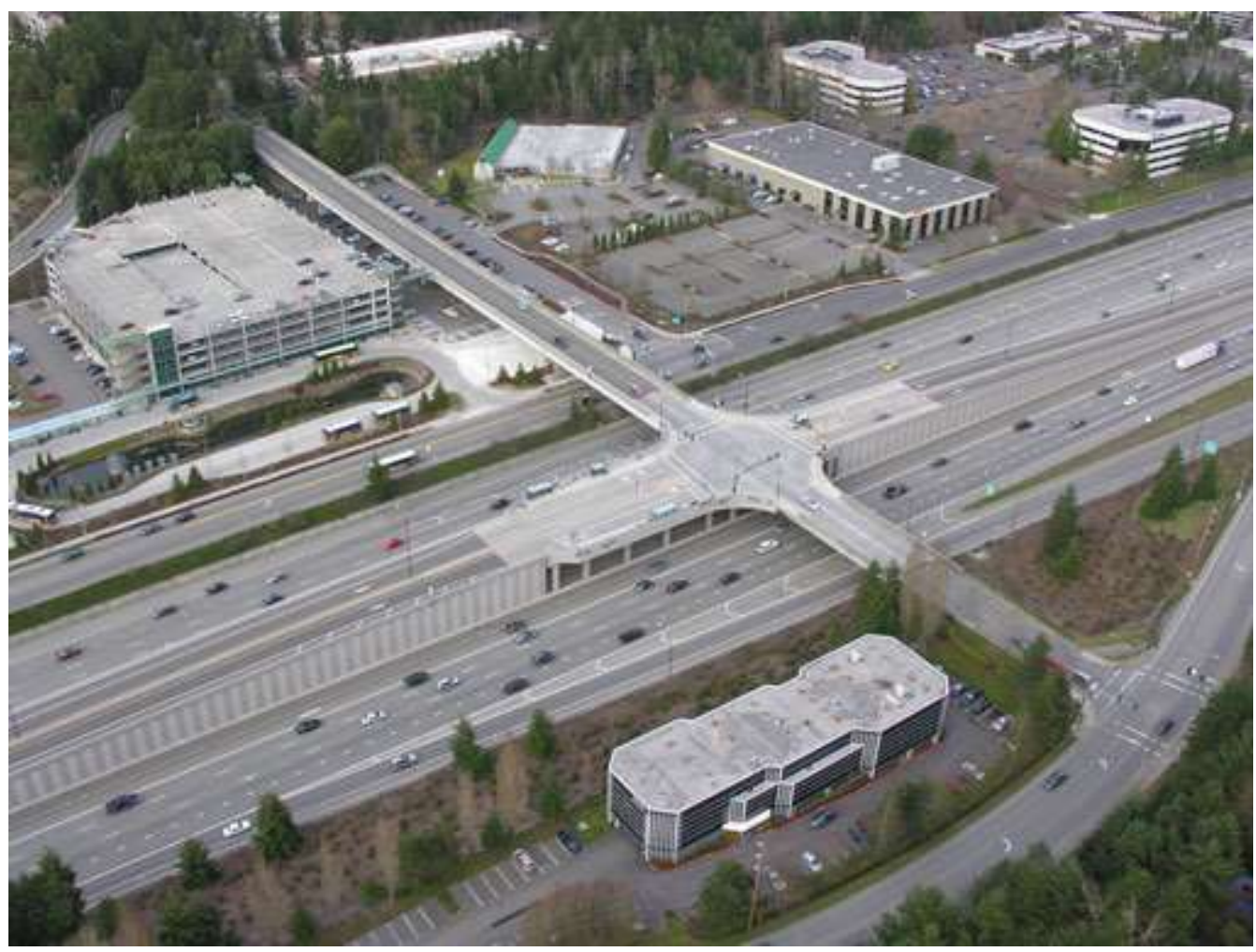

Fig. 9 Ramp system in I-90 in Seattle

It should be taken into consideration that a decent and safe HOV lane control incorporates auxiliary lanes, flyover ramps and enforcement areas. The cost and space required for a safe control of HOV lane could be almost like the cost and space needed for a new general purpose lane; however, the throughput of two general purpose lanes is obviously significantly better than the throughput of one HOV lane, so the costeffectiveness of HOV lanes is very questionable [31]. An example of ramp system from I-90 in Seattle is shown in Figure 9.

\section{CONCLUSIONS}

The HOV lanes have a very little success in convincing people to carpool. In [32] the author noticed that HOV lanes have a negligible effect on carpools - the share of commuters who carpool in the US has been significantly reduced. While the percentage of commuters who carpool was $14.1 \%$ in 1985, in 2003 it was dropped to only $8.7 \%$ even though the authorities have constructed free parking lots near the beginning of HOV lanes for carpoolers, have encouraged matching platforms for carpools and in some cases even have subsidies carpools.

There are several reasons for the decline in carpooling [33] like the growth of suburbs, more vehicles on the roads, decline in the ratio of gasoline and the average wage, which made the gasoline actually more economical.

However, the HOV lanes have an insignificant influence on the share of carpools [34]. The inherent absurdity of a method aiming at alleviating traffic congestions that works only when traffic congestions exist have made the method in actual fact unproductive.

\section{REFERENCES}

[1] J. E. Hughes and D. Kaffine, "When should drivers be encouraged to carpool in hov lanes?", Economic Inquiry, Vol. 57, No. 1, pp.667-684, (2019). 
[2] J. Plotz, K. Konduri and R. Pendyala. "To What Extent Can High-Occupancy Vehicle Lanes Reduce Vehicle Trips and Congestion?" Transportation Research Record: Journal of the Transportation Research Board, Vol. 2178, No. 1, pp. 170-176, (2010).

[3] J. Kwon and P. Varaiya. "Effectiveness of California's high occupancy vehicle (HOV) system", Transportation Research Part C: Emerging Technologies, Elsevier B. V., Vol. 16, No. 1, pp. 98-115, (2008).

[4] J. Dahlgren, "High occupancy vehicle lanes: Not always more effective than general purpose lanes", Transportation Research Part A: Policy and Practice, Vol. 32, No. 2, Elsevier B. V., pp .99-114, (1998).

[5] B. Newell and C. Doll, "Systems Thinking and the Cobra Effect", Our World, (2015).

[6] G. Giuliano, D. W. Levine and R. F. Teal, "Impact of high occupancy vehicle lanes on carpooling behavior", Transportation, Vol. 17, No. 2, pp. 159-177, (1990).

[7] A. Guin, M. Hunter and R. Guensler, "Analysis of reduction in effective capacities of high-occupancy vehicle lanes related to traffic behavior", Transportation Research Record, Vol. 2065, No. 1, pp. 47-53, (2008).

[8] J. Dahlgren, "Are HOV lanes really better?", ACCESS, The University of California Transportation Center, Vol. 6, pp. 25-29, (1995).

[9] J. Dahlgren, "High-occupancy/toll lanes: where should they be implemented?", Transportation Research Part A: Policy and Practice, Elsevier B.V. Publication Inc., Vol. 36, No. 3, pp. 239-255, (2002).

[10] Katherine F. Turnbull, "Potential Impact of Exempt Vehicles on HOV Lanes", Texas Transportation Institute, The Texas A\&M University, (2005). Available at: https://ops.fhwa.dot.gov/publications/exemptvehicleshov/pdf/exemptvehiclesrpt.pdf

[11] J. Berger, "Our Towns; H.O.V. Lanes: A 30-Mile Test That Failed", The New York Times, (1998). available at: https://www.nytimes.com/1998/12/01/nyregion/our-towns-hov-lanes-a-30-mile-test-thatfailed.html

[12] K. F. Turnbull and T. DeJohn, "New Jersey I-80 and I-287 HOV Lane Case Study", Texas Transportation Institute, The Texas A\&M University, (2000).

[13] J. Kendall, "Chaos on a Freeway: New System Jams West Side Traffic", Los Angeles Times, (1976).

[14] H. Simkowitz, "Southeast Expressway High Occupancy", Vehicle Lane Evaluation Report", Office of Transportation Planning Management and Demonstrations, U.S. Department of Transportation, (1978).

[15] Y. Hasegawa and H. Kato. "Intra-household Joint Car Travel under the 3-in-1 Policy in Jakarta Metropolitan Area, Indonesia", Journal of the Eastern Asia Society for Transportation Studies, Vol. 12, pp. 522-537, (2017).

[16] Y. Wiseman, "Autonomous Vehicles", Encyclopedia of Organizational Knowledge, Administration and Technologies, First Edition, (2020).

[17] USA National Highway Traffic Safety Administration, "Automated Vehicles for Safety", (2019), available online at: https://www.nhtsa.gov/technology-innovation/automated-vehicles-safety

[18] P. M. Bösch, F. Becker, H. Becker and K. W. Axhausen. "Cost-based analysis of autonomous mobility services", Transport Policy Vol. 64, pp. 76-91, (2017).

[19] Y. Wiseman, "Driverless Cars will Make Union Stations Obsolete", The Open Transportation Journal, Vol. 13, pp. 109-115, (2019).

[20] Y. Wiseman, "Driverless Cars will Make Passenger Rails Obsolete", IEEE Technology and Society, Vol. 38(2), pp. 22-27, (2019).

[21] Y. Wiseman, "In an Era of Autonomous Vehicles, Rails are Obsolete", International Journal of Control and Automation, Vol. 11(2), pp. 151-160, (2018).

[22] Y. Wiseman, "Remote Parking for Autonomous Vehicles", International Journal of Hybrid Information Technology, Vol. 10, No. 1, pp. 313-324, (2017).

[23] Y. Wiseman, "Self-Driving Car - A Computer will Park for You", International Journal of Engineering \& Technology for Automobile Security, Global Vision School Publication, Vol. 1, No. 1, pp. 9-16, (2017).

[24] D. C. Shoup, "The High Cost of Free Parking", Planners Press, American Planning Association, (2005).

[25] P. Fernandes and U. Nunes, "Platooning with IVC-enabled autonomous vehicles: Strategies to mitigate communication delays, improve safety and traffic flow", IEEE Transactions on Intelligent Transportation Systems, Vol. 13, No. 1, pp. 91-106, (2012).

[26] D. Carlino, M. Depinet, P. Khandelwal and P. Stone. "Approximately orchestrated routing and transportation analyzer: Large-scale traffic simulation for autonomous vehicles", In 15th International IEEE Conference on Intelligent Transportation Systems (ITSC), Anchorage, Alaska, pp. 334-339, (2012).

[27] S. Lam, and J. Katupitiya, "Cooperative autonomous platoon maneuvers on highways", 2013 IEEE/ASME International Conference on Advanced Intelligent Mechatronics, Wollongong, Australia, pp. 1152-1157, (2013).

[28] Y. Wiseman, "Ancillary Ultrasonic Rangefinder for Autonomous Vehicles", International Journal of Security and its Applications, Science and Engineering Research Support Society (SERSC), Vol. 12, No. 5, pp. 49-58, (2018).

[29] Y. Wiseman, "Blaumilch Canal on Ayalon Highway", Daaton, (2015), Available online at: http://www.daaton.co.il/Article.aspx?id=3290 
[30] About Iran, "Second floor of Sadr highway was inaugurated", (2013), Available online at: https://www.youtube.com/watch?v=5G1s0sE5-zc

[31] J. W. Dahlgren, "An Analysis of the Effectiveness of High Occupancy Vehicle Lanes", Ph.D. dissertation, University of California, Berkeley, (1994).

[32] S. Shewmake, "Can carpooling clear the road and clean the air? Evidence from the literature on the impact of HOV lanes on VMT and air pollution", Journal of Planning Literature, Vol. 27, No. 4, pp. 363-374, (2012).

[33] C. K. Orski, "Carpool Lanes - An Idea Whose Time Has Come and Gone. Point of View", Transportation Research Board, Vol. 214, pp. 24-26, (2001).

[34] E. Ferguson, "The rise and fall of the American carpool: 1970-1990", Transportation, Vol. 24, No. 4, pp. 349-376, (1997). 